\title{
Additive manufacturing with the lightweight material aluminium alloy EN AW-7075
}

\author{
Anika Langebeck $^{1}$ (D) $\cdot$ Annika Bohlen ${ }^{1} \cdot$ Hannes Freisse ${ }^{1} \cdot$ Frank Vollertsen $^{1,2}$
}

Received: 13 May 2019 / Accepted: 12 November 2019/Published online: 4 December 2019

(C) The Author(s) 2019

\begin{abstract}
As a widely used additive manufacturing technique, the laser metal deposition process (LMD) also known as direct energy deposition (DED) is often used to manufacture large-scale parts. Advantages of the LMD process are the high build-up rate as well as its nearly limitless build-up volume. To manufacture large-scale parts in lightweight design with high strength aluminium alloy EN AW-7075, the LMD process has a disadvantage that must be considered. During the process, the aluminium alloy is melted and has therefore a high solubility for hydrogen. As soon as the melt pool solidifies again, the hydrogen cannot escape the melt and hydrogen pores are formed which weakens the mechanical properties of the manufactured part. To counter this disadvantage, the hydrogen must be successfully kept away from the process zone. Therefore, the covering of the process zone with shielding gas can be improved by an additional shielding gas shroud. Furthermore, the process parameters energy input per unit length as well as the horizontal overlapping between two single tracks can be varied to minimize the pore volume. Best results can be achieved in single tracks with an elevated energy input per unit length from 3000 to $6000 \mathrm{~J} / \mathrm{cm}$. To manufacture layers, a minimal horizontal overlapping will lead to lowest pore volume, although this results in a very wavy surface, as a compromise of low pore volume and a nearly even surface a horizontal overlapping of 30 to $37 \%$ leads to a pore volume of $0.95 \% \pm 0.50 \%$.
\end{abstract}

Keywords Laser metal deposition · Direct energy deposition · EN AW-7075 · Porosity

\section{Introduction}

Additive manufacturing technologies have become more and more relevant for industrial applications during the last years [1]. For metal additive manufacturing, various energy sources like laser beam, electron beam or arc are used with particular advantages and disadvantages [2]. Using a laser beam as energy source is beneficial due to the locally low heat input. For

Recommended for publication by Commission IV - Power Beam Processes

This is part of the collection Additive Manufacturing - Processes, Simulation and Inspection

Anika Langebeck

langebeck@bias.de

1 BIAS - Bremer Institut fuer angewandte Strahltechnik GmbH, Klagenfurter Str. 5, 28359 Bremen, Germany

2 Faculty Production Technology, University of Bremen, Bibliothekstr. 1, 28359 Bremen, Germany diverse applications, different laser beam systems can be used. Small-scale parts with complex geometries and high resolution can be additively manufactured via the powder-bed-based process laser beam melting (LBM). To reach a high resolution, a high beam quality with a small focus diameter is mandatory. For this fibre lasers with a comparatively low laser power up to $1 \mathrm{~kW}$ are used. If large-scale parts are desired, an openspace process like laser metal deposition (LMD) also known as direct energy deposition (DED) is advantageous. The process provides a much larger build-up volume only limited by the travels of the axis system. By using a defocused highpower laser with a larger spot diameter with laser power up to $10 \mathrm{~kW}$ high build-up rates up to $18 \mathrm{~kg} / \mathrm{h}$ depending on the used material are possible [3]. In contrast to LBM, the LMD process enables not only the use of powder, but the usage of wire material as well. With wire, it is possible to reach nearly $100 \%$ of the material. The advantage of using powder instead of wire for additive processes is the possibility to mix several powders in situ for example for a graded material composition in the component [4]. As deposition, material metal powder or wire is often used. The powder-based techniques can be 
divided into powder-bed-based processes like laser beam melting (LBM) and open-space processes like laser metal deposition (LMD) also known as direct energy deposition (DED) [2]. Whereas LBM is commonly used to manufacture small parts with complex geometries in high resolution, LMD is more suitable to produce large-scaled parts. This is due to the high build-up rate during the LMD process and the nearly limitless build-up volume. This enables to manufacture large parts in comparatively short time and nearly without any restrictions by no need of use of a process chamber, as with LBM. A large variety of metal powders is suitable for additive manufacturing such as tool steel [5], aluminium alloys [6] and copper alloys [7].

Due to the development towards a more energy-efficient design through mass reduction, aluminium alloys are of importance for the additive production of innovative lightweight components. However, aluminium alloys show the disadvantage of pore formation during additive processing which must be considered. There are different approaches to overcome this disadvantage. On the one hand, postprocessing can be carried out, such as hot isostatic pressing or friction stir processing to reach fully dense parts [8], though these approaches are limited to simple geometries. On the other hand, there are several approaches to limit the formation of porosity already during the additive manufacturing process. It is known that pore formation in aluminium during laser welding is mainly affected by the surface conditions, the shielding gas and the used process parameters [9]. During the LMD process, the substrate material and the powder are melted and then undergo a rapid solidification [10]. While the aluminium alloy is in the molten state, it has a high solubility for hydrogen. Due to the rapid solidification and the concomitant large decrease in solubility for hydrogen, the gas cannot completely escape the melt pool; hydrogen pores remain in the weld bead [11]. The most important sources of hydrogen for porosity in aluminium alloy weld beads are the filler material, the shielding gas and the substrate material [11]. As even under unfavourable storage conditions, the hydrogen content in aluminium alloys increases only marginally [12]; the main source of hydrogen for porosity are the substrate material with its contaminants as well as oxide layer and the ambient gas. Cleaning the substrate's surface before starting the process can reduce hydrogen-caused porosity during the process [13]. Additionally, a reliable covering of the process zone with shielding gas can contribute to the effective avoidance of hydrogen pores. This is supported by aluminium alloy specimens manufactured by LBM. The use of a process chamber for LBM enables a defined and constant shielding gas coverage. With a sufficient energy density $>$ 99.5\%, dense aluminium parts can be manufactured [14]. Process parameters like laser power and welding speed during additive manufacturing are also known to be important influencing factors to minimise porosity [15]. Whereas the influence of the horizontal overlapping between single tracks during manufacturing layers out of aluminium alloy powder by LMD on porosity is not studied yet.

In this study, the influence of improved shielding gas coverage as well as the influence of the process parameters horizontal overlapping and energy input per unit length, as a quotient of laser power and welding speed, will be analysed. Therefore, an improved shielding gas coverage was developed. The analysis was carried out on single tracks and layers consisting of several single tracks for aluminium alloy EN AW-7075.

\section{Experimental}

\subsection{Equipment}

For the LMD process, a lamp pumped Nd: YAG rod laser in cw mode has been used. The Trumpf HL 4006 D has a wavelength of $1064 \mathrm{~nm}$ and a maximum laser power of $4 \mathrm{~kW}$. The beam was guided via an optical fibre with core diameter of $600 \mu \mathrm{m}$ to the optical unit Trumpf BEO D 70 with a collimation lens and a focus lens with a focal length of $200 \mathrm{~mm}$ respectively. The powder was guided from the powder feeder Sulzer Metco Twin 10C to the coaxial three-jet powder nozzle made by Ixun Lasertechnik GmbH. Argon was used as carrier gas with a flow rate between 4.1 and $5.5 \mathrm{l} / \mathrm{min}$. The distance from the nozzle to the substrate was $12 \mathrm{~mm}$. The powder focus was located on the substrate's surface and was aligned to the laser beam. As traversing unit, a 3-axis CNC made by Foehrenbach Positioniersysteme GmbH driven by the control unit PA8000 made by Power Automation GmbH has been used.

\subsection{Material}

As powder material gas-atomised aluminium alloy, EN AW-7075 with a particle size D10 $37 \mu \mathrm{m}$ and D90 $122 \mu \mathrm{m}$ supplied by NMD New Material Development $\mathrm{GmbH}$ was used. The powder was sieved with $50-\mu \mathrm{m}$ and $125-\mu \mathrm{m}$ mesh size. Table 1 shows the results of a chemical analysis in accordance with EN 10204 3.1. As a substrate milled aluminium alloy, EN AW-5083 with $50 \mathrm{~mm}$ length and width and $10 \mathrm{~mm}$ height was used (see Table 1 for chemical composition according the supplier's (Amco $\mathrm{GmbH}$ ) information). The substrate's surface was cleaned with ethanol before starting the process.

\subsection{Influence of shielding gas concept}

The influence of two shielding gas concepts on the pore volume was studied based on 35-mm-long single tracks. For 
Table 1 Chemical composition of the batch of powder material EN AW-7075 in accordance with EN 102043.1 chemical composition of substrate material EN AW-5083 provided by the supplier

\begin{tabular}{llllllllll}
\hline & $\mathrm{Al}$ in $\%$ & $\mathrm{Si}$ in $\%$ & $\mathrm{Fe}$ in $\%$ & $\mathrm{Mn}$ in $\%$ & $\mathrm{Zn}$ in $\%$ & $\mathrm{Mg}$ in $\%$ & $\mathrm{Cu}$ in $\%$ & $\mathrm{Cr}$ in $\%$ & $\mathrm{Ti}$ in $\%$ \\
\hline AW-7075 & 89.9 & 0.11 & 0.09 & 0.01 & 5.51 & 2.42 & 1.60 & 0.21 \\
$\mathrm{AW}-5083$ & bal. & 0.4 & 0.4 & 0.4 to 1 & 0.25 & 4 to 4.9 & 0.1 & 0.05 to 0.25 & 0.15 \\
\hline
\end{tabular}

shielding gas concept 1 , the centric guidance in the powder nozzle for the laser beam was used to cover the process zone with shielding gas. For shielding gas concept 2, an additional shroud was used, which also supplies shielding gas (see Fig. 1). See Table 2, column "Influence of shielding gas concept" for specific process parameters.

The pore volume was measured via X-ray computer tomography with v|tome|x m 240 "research edition" pxSD09 made by GE Sensing \& Inspection Technologies GmbH with a resolution of $40 \mu \mathrm{m}$.

\subsection{Influence of energy input per unit length and horizontal overlapping}

The influence of the quotient of laser power and welding speed, the energy input per unit length, was studied based on 35-mm-long single tracks. The laser energy was varied between 2 and $4 \mathrm{~kW}$ in $0.5 \mathrm{~kW}$ steps. The welding speed was not varied to have a constant powder mass flow per unit length (see Table 2 for specific process parameters).

The influence of horizontal overlapping on pore volume was studied based on layers out of three $35-\mathrm{mm}$ single tracks. A unidirectional build strategy was chosen. The horizontal overlapping $16 \%, 23 \%, 30 \%, 37 \%, 44 \%$ and $51 \%$ was chosen (see Table 2 for specific process parameters). Each parameter combination was examined in randomized triple determination.
Additional experiments were done to determine whether the porosity is mainly formed due to the condition of the substrate material or feeding powder into the process zone. For this, tests were carried with feeding powder on the one hand and without feeding powder on the other hand. The process parameters can be found in Fig. 4.

The pore volume was determined in cross sections, which were wet sanded for $5 \mathrm{~min}$ with $\mathrm{SiC}$ abrasive paper P1200 grain and polished for $5 \mathrm{~min}$ and $10 \mathrm{~min}$ with $3-\mu \mathrm{m}$ diamond suspension and $0.04 \mu \mathrm{m} \mathrm{SiO}_{\mathrm{x}}$ suspension, respectively. The software used to determine the pore volume was Olympus Stream Enterprise Desktop.

\section{Results}

\subsection{Influence of shielding gas concept}

For the conventional shielding gas concept 1 with shielding gas through the centric beam guidance, a pore volume in a single track of $2.25 \%$ was measured by computer tomography. Increasing the shielding gas flow via the additional shroud (shielding gas concept 2) led to a decreased porosity of $1.78 \%$ in a single track. Figure 2 shows the pore distribution within the single tracks as a false-colour image.
Fig. 1 Powder nozzle with centric guidance for shielding gas and laser beam and additional shroud coaxial to the laser beam

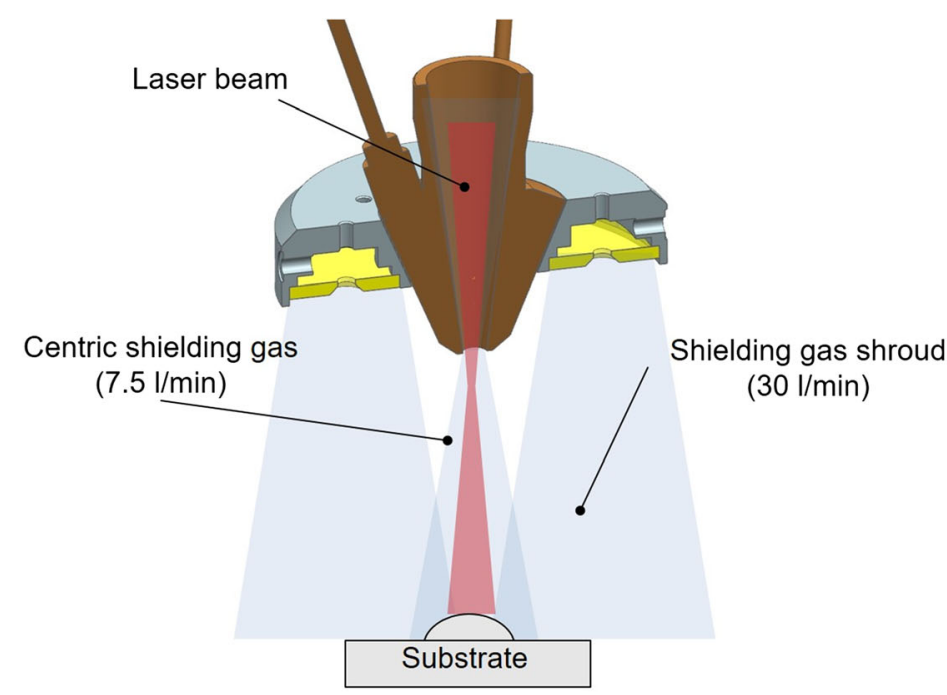

Langebeck 2018

BIAS ID 182110 
Table 2 Process parameters

\begin{tabular}{|c|c|c|c|}
\hline & Influence of shielding gas concept & Influence of energy input per unit length & Influence of horizontal overlapping \\
\hline Laser power & $2.4 \mathrm{~kW}$ & 2 to $4 \mathrm{~kW}$ & $4 \mathrm{~kW}$ \\
\hline Laser spot diameter & $2.0 \mathrm{~mm}$ & $4.5 \mathrm{~mm}$ & \\
\hline Shielding gas flow (1) & $7.51 /$ min (centric) & - & \\
\hline \multirow[t]{2}{*}{ Shielding gas flow (2) } & $7.51 / \mathrm{min}$ (centric) & $7.5 \mathrm{l} / \mathrm{min}$ (centric) & \\
\hline & $301 /$ min (shroud) & $301 /$ min (shroud) & \\
\hline Carrier gas flow & $5.51 / \mathrm{min}$ & $4.11 / \mathrm{min}$ & \\
\hline Powder feed rate & $(9.9 \pm 0.2) \mathrm{g} / \mathrm{min}$ & $(9.3 \pm 0.3) \mathrm{g} / \mathrm{min}$ & $(8.1 \pm 0.4) \mathrm{g} / \mathrm{min}$ \\
\hline Welding speed & $400 \mathrm{~mm} / \mathrm{min}$ & $400 \mathrm{~mm} / \mathrm{min}$ & \\
\hline Number of tracks & 1 & 1 & 3 \\
\hline Horizontal overlapping & - & - & 16 to $51 \%$ \\
\hline
\end{tabular}

\subsection{Influence of energy input per unit length and horizontal overlapping}

The influence of the energy input per unit length on the pore volume is shown in Fig. 3.

The pore volume decreased with increasing energy input per unit length. The lowest pore volume of $0.09 \% \pm 0.07 \%$ was measured for highest energy input per unit length of $6000 \mathrm{~J} / \mathrm{cm}$ with a laser energy of $4 \mathrm{~kW}$ and a welding speed of $400 \mathrm{~mm} / \mathrm{min}$. The powder usage efficiency of $82.0 \% \pm$ $3.4 \%$ was not affected by varying the energy input per unit length between and $6000 \mathrm{~J} / \mathrm{cm}$.

During the additional experiments with and without feeding powder into the process zone, similar low porosity of $0.15 \% \pm 0.05 \%$ was measured for the specimens without feeding powder. For the additive process with feeding powder, higher porosity of $0.52 \% \pm 0.15 \%$ was measured (see Fig. 4).
The influence of the horizontal overlapping on the pore volume is shown in Fig. 5. The pore volume increased with increasing horizontal overlapping. The lowest pore volume measured in triple determination of $0.41 \% \pm 0.18 \%$ was measured for horizontal overlapping of $23 \%$. However, the low horizontal overlapping of $23 \%$ led to a wavy surface (see Fig. 6), as a compromise of low pore volume and a more even surface led a horizontal overlapping of 30 to $37 \%$ with a pore volume of $0.95 \% \pm 0.50 \%$. The powder usage efficiency of $82.8 \% \pm 1.0 \%$ was not affected by varying the horizontal overlapping between 16 and $51 \%$.

In the shown cross section of the layer with a horizontal overlapping of $30 \%$ in Fig. 6 pore clusters along the weld bead interfaces between two single tracks are visible. These clusters are also more or less present in the other layers with varying horizontal overlapping. Figure 7 shows these clusters very

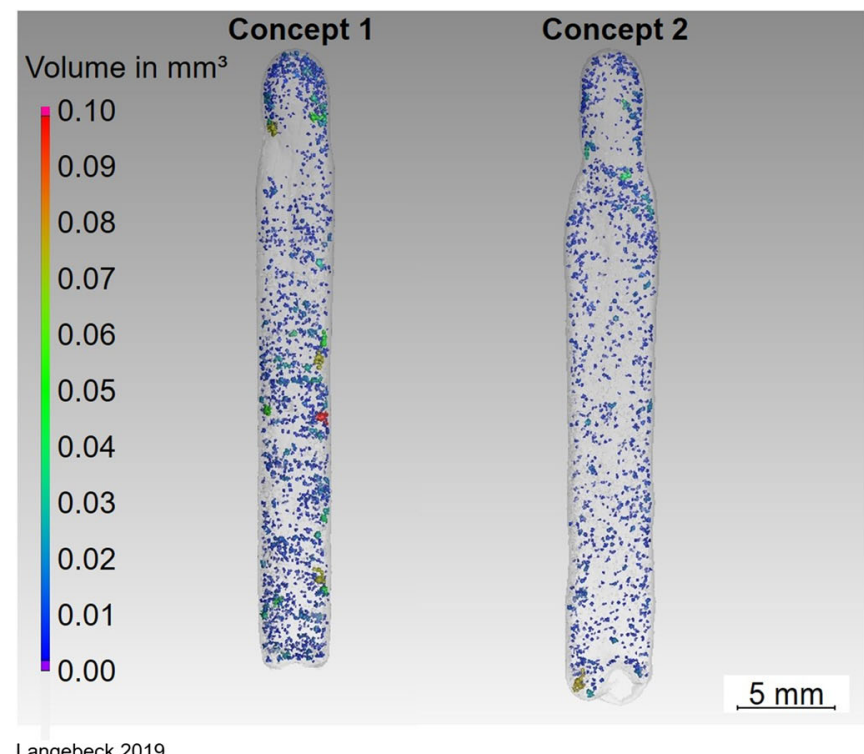

\begin{tabular}{|c|c|}
\hline ocess parameters & \\
\hline Laser & HL $4006 \mathrm{D}$ \\
\hline Optical unit & Trumpf BEO D70 \\
\hline Powder nozzle & Ixun 3-jet nozzle \\
\hline Laser power & $2.4 \mathrm{~kW}$ \\
\hline$\varnothing$ Laser spot (calculated) & $2 \mathrm{~mm}$ \\
\hline Shielding gas flow (1) & $7.5 \mathrm{l} / \mathrm{min}$ (centric) \\
\hline Shielding gas flow (2) & $\begin{array}{l}7.5 \mathrm{l} / \mathrm{min} \text { (centric) } \\
30 \mathrm{l} / \mathrm{min} \text { (shroud) }\end{array}$ \\
\hline Carrier gas flow & $5.5 \mathrm{l} / \mathrm{min}$ \\
\hline Welding speed & $400 \mathrm{~mm} / \mathrm{min}$ \\
\hline Substrate & EN AW-5083 \\
\hline Powder & EN AW-7075 \\
\hline Powder feed rate & $(9.9 \pm 0.2) \mathrm{g} / \mathrm{min}$ \\
\hline Build-up rate & $184 \mathrm{~cm}^{3} / \mathrm{h}$ \\
\hline Results & \\
\hline Porosity (concept 1) & $2.25 \%$ \\
\hline Porosity (concept 2) & $1.78 \%$ \\
\hline
\end{tabular}

Fig. 2 False-colour image of pore distribution within single tracks. Concept 1: centric shielding gas supply. Concept 2: centric shielding gas supply and additional shielding gas shroud 
Fig. 3 Influence of energy input per unit length on pore volume (black circles) as well as on powder usage efficiency (black crosses)

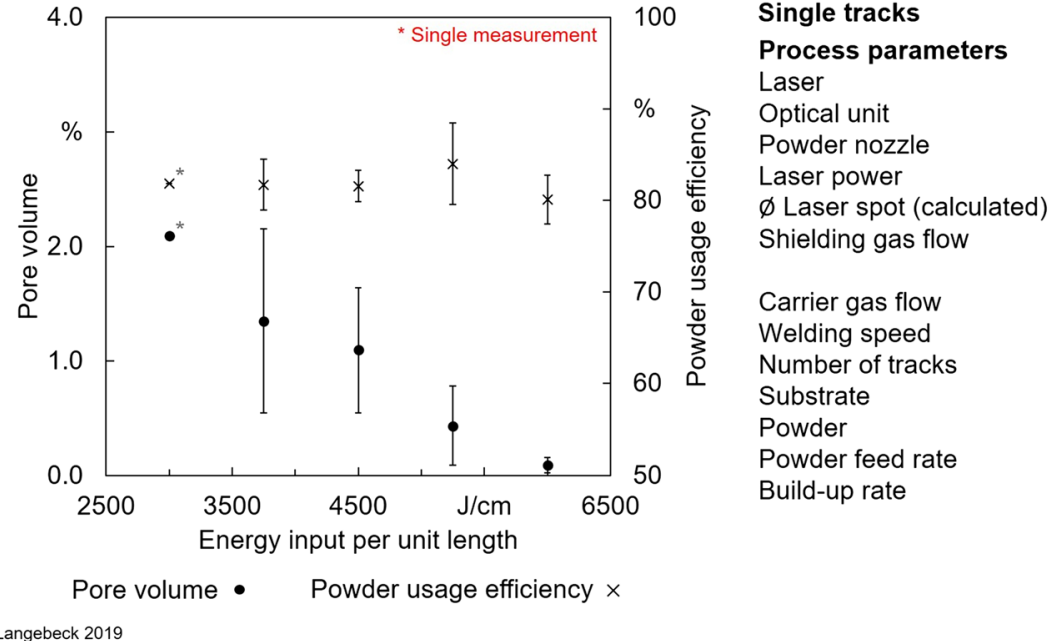

HL 4006 D

Trumpf BEO D70

Ixun 3-jet nozzle

$2.0 \mathrm{~kW}$ to $4.0 \mathrm{~kW}$

$4.5 \mathrm{~mm}$

$7.5 \mathrm{l} / \mathrm{min}$ (centric)

$30 \mathrm{l} / \mathrm{min}$ (shroud)

$4 \mathrm{l} / \mathrm{min}$

$400 \mathrm{~mm} / \mathrm{min}$

EN AW-5083

EN AW-7075

$(9.3 \pm 0.3) \mathrm{g} / \mathrm{min}$

$(164 \pm 10) \mathrm{cm}^{3} / \mathrm{h}$ clearly between the first and the second weld bead in a cross section of a layer with $23 \%$ horizontal overlapping.

\section{Discussion}

An improved shielding gas coverage of the process zone with an additional shroud led to a decrease in porosity. This is due to an improved displacement of the ambient air from the process zone through the additional shielding gas flow. Since hydrogen is known to be a major source of pores in aluminium alloy weld beads, a more effective displacement of humid, hydrogen-containing ambient air will lower the pore volume [16]. Though, it is unclear whether an increased shielding gas flow only through the centric guidance would lead to the same decrease in pore volume or whether the large-area distribution of the additional shielding gas through the shroud is necessary. Despite the fact, that the values for the comparison of these two variations were done as single experiments and not triple determination, the results indicate that additional shielding gas supplied via the shroud will lead to lower porosity.

A higher energy input per unit length leads to a larger and more overheated melt pool with a smaller spatial temperature gradient. As a result, the cooling rate and therefore the solidification rate is lower and gaseous elements such as hydrogen have more time for degassing, pore volume is decreasing. Additionally, the higher thermocapillary convection in the melt pool due to the higher energy input per unit length contributes the decrease of the cooling rate [17].

The lowest pore volume in specimens manufactured via LMD is reached in single tracks. Manufacturing layers out of several single tracks with a horizontal overlapping led to an increase in porosity. This is due to the oxide layer, which formed on the rough surface of the preceding weld bead with adhering powder particles. Besides others, the oxide layer on aluminium alloys in its hydrate form is considered an important source for pores in weld beads
Fig. 4 Pore volume in single tracks with and without feeding powder into the process zone. Please note that a different laser source with adapted process parameters was used

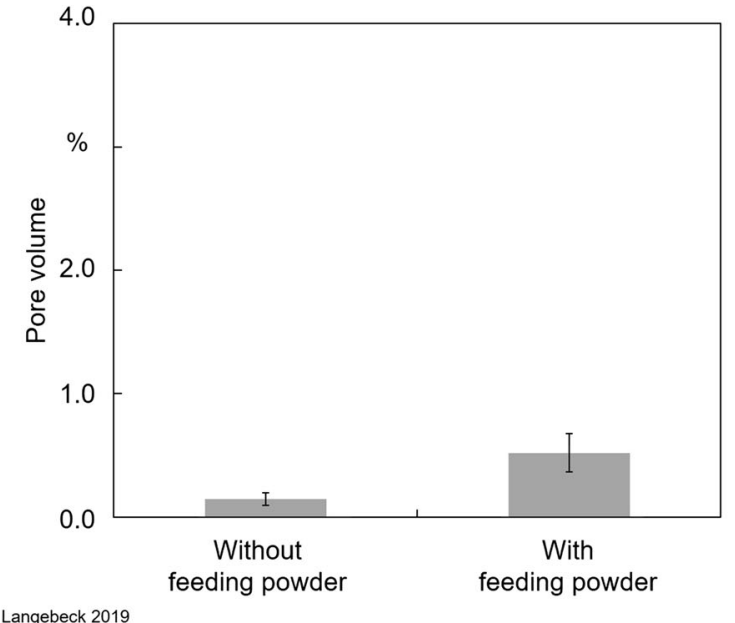

$\begin{array}{lr}\begin{array}{lr}\text { Single tracks } \\ \text { Process parameters } \\ \text { Laser }\end{array} & \text { TruDisk } 12002 \\ \text { Wavelength } & 1030 \mathrm{~nm} \\ \text { Fibre diameter } & 0.2 \mathrm{~mm} \\ \text { Collimation lens } & 51 \mathrm{~mm} \text { to } 115 \mathrm{~mm} \\ \text { Focus lens } & 460 \mathrm{~mm} \\ \text { Powder nozzle } & \text { Ixun 3-jet nozzle } \\ \text { Laser power } & 4.0 \mathrm{~kW} \\ \varnothing \text { Laser spot (calculated) }) & 1.8 \mathrm{~mm} \text { to } 0.8 \mathrm{~mm} \\ \text { Shielding gas flow } & 7.5 \mathrm{l} / \mathrm{min}(\text { centric) } \\ & 30 \mathrm{l} / \mathrm{min}(\text { shroud) } \\ \text { Carrier gas flow } & 3.5 \mathrm{l} / \mathrm{min} \\ \text { Welding speed } & 400 \mathrm{~mm} / \mathrm{min} \\ \text { Substrate } & \text { EN AW-5083 } \\ \text { Powder } & \text { EN AW-7075 } \\ \text { Powder feed rate } & (9.8 \pm 0.4) \mathrm{g} / \mathrm{min} \\ & \\ & \text { BIAS ID } 190289\end{array}$


Fig. 5 Influence of horizontal overlapping on pore volume (black circles) as well as powder usage efficiency (black crosses)

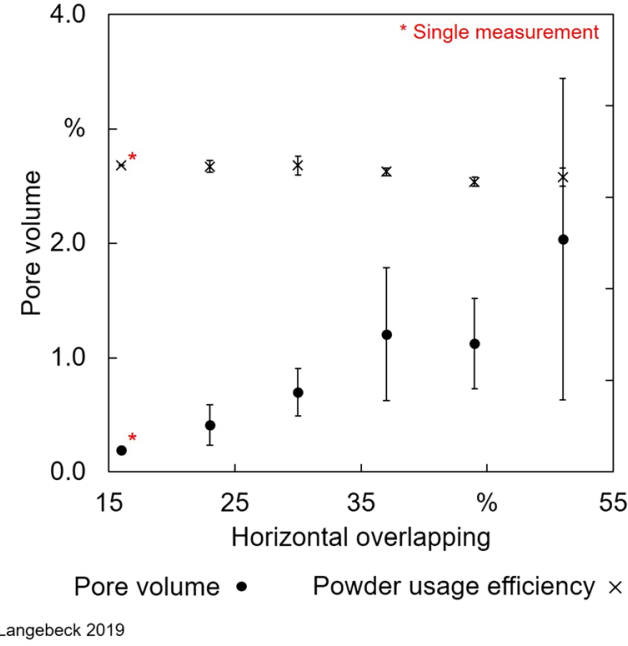

Langebeck 2019
Layers

Process parameters

Laser

Optical unit

Powder nozzle

Laser power

$\varnothing$ Laser spot (calculated)

Shielding gas flow

Carrier gas flow

Welding speed

Number of tracks

Substrate

Powder

Powder feed rate

Build-up rate
HL 4006 D

Trumpf BEO D70

Ixun 3-jet nozzle

$4.0 \mathrm{~kW}$

$4.5 \mathrm{~mm}$

$7.5 \mathrm{l} / \mathrm{min}$ (centric) $30 \mathrm{l} / \mathrm{min}$ (shroud)

$4 \mathrm{l} / \mathrm{min}$

$400 \mathrm{~mm} / \mathrm{min}$

EN AW-5083

EN AW-7075

$(8.1 \pm 0.4) \mathrm{g} / \mathrm{min}$

$(144 \pm 6) \mathrm{cm}^{3} / \mathrm{h}$

BIAS ID 190280

[18]. Since higher temperatures of aluminium alloy result in a thicker oxide layer [19], the surface of the preceding weld bead is a source for high porosity in the subsequent weld bead, which is welded with a high horizontal overlapping. This assumption is supported by clusters of pores along the weld bead interfaces between two single tracks (see Fig. 7).

The formation of porosity is affected by feeding the powder into the process zone. This is shown by the results of the additional studies in which the porosity of remelted specimens (without feeding powder) was determined. The significant lower porosity can possibly be explained by two different considerations. On the one hand, the shielding gas coverage could be disturbed by the powder flow. This enables humid, hydrogen-containing ambient air to affect the process zone and results in higher porosity. On the other hand, the results for the layers out of several single tracks showed that the interfaces of the preceding weld beads with their oxide layers significantly influenced the porosity. The powder particles are also surrounded by an oxide layer [20], which is why additional hydrogen is probably already introduced into the process zone with the powder.

\section{Conclusions}

The results can be concluded as follows:

- The pore volume in additively manufactured EN AW7075 specimens can be successfully reduced by adapting the shielding gas coverage of the process zone. Therefore, an additional shroud was developed.

- Adapting the process parameters during LMD of EN AW7075 towards higher energy input per unit length up to $6000 \mathrm{~J} / \mathrm{min}$, a significant lower porosity can be measured.
Fig. 6 Cross sections of layers out of three single tracks with different horizontal overlapping

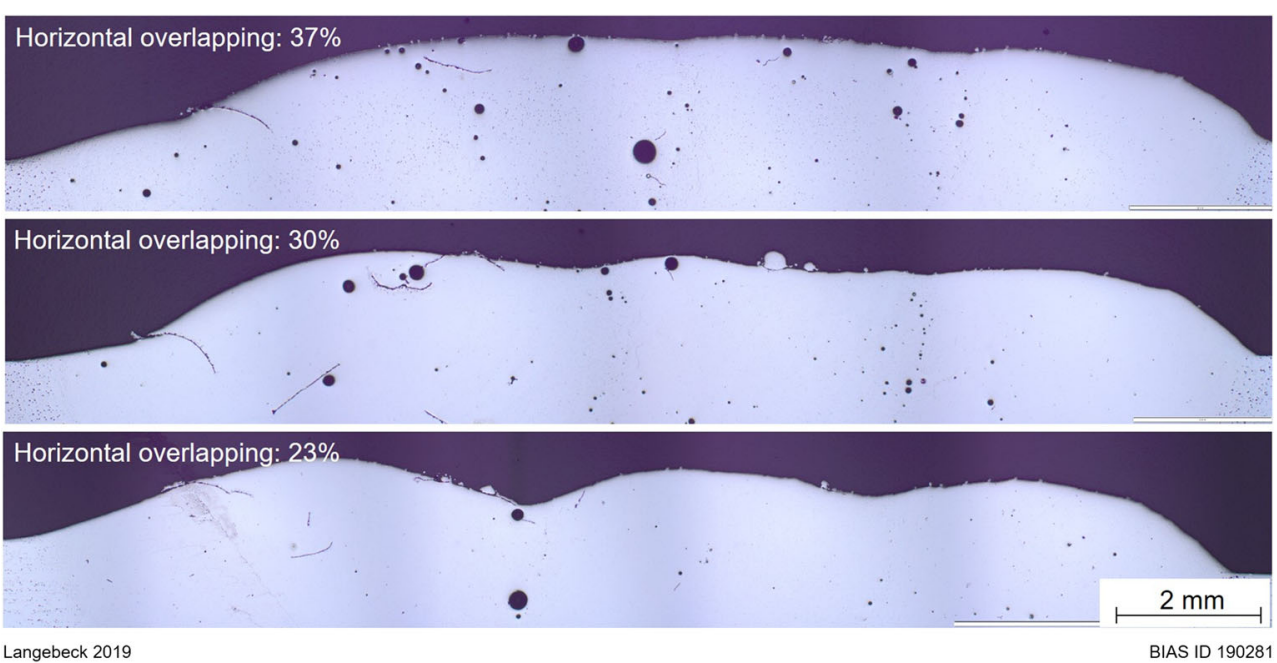




\section{Layers}

Process parameters

Laser

Bearbeitungskopf

Powder nozzle

Laser power

$\varnothing$ Laser spot (calculated)

Shielding gas flow

$\begin{aligned} \text { HL 4006 D } & \text { Welding speed } \\ \text { Trumpf BEO D70 } & \text { Number of tracks } \\ \text { Ixun 3-jet nozzle } & \text { Horizontal overlapping } \\ 4.0 \mathrm{~kW} & \text { Substrate } \\ 4.5 \mathrm{~mm} & \text { Powder } \\ 7.5 \mathrm{l} / \mathrm{min} \text { (centric) } & \text { Powder feed rate } \\ 30 \mathrm{l} / \mathrm{min} \text { (shroud) } & \text { Build-up rate }\end{aligned}$

$400 \mathrm{~mm} / \mathrm{min}$
3
$23 \%$
EN AW -5083
EN AW- 7075
$.1 \pm 0.4) \mathrm{g} / \mathrm{min}$
$144 \pm 6) \mathrm{cm} / \mathrm{h}$

Carrier gas flow $4 \mathrm{l} / \mathrm{min}$

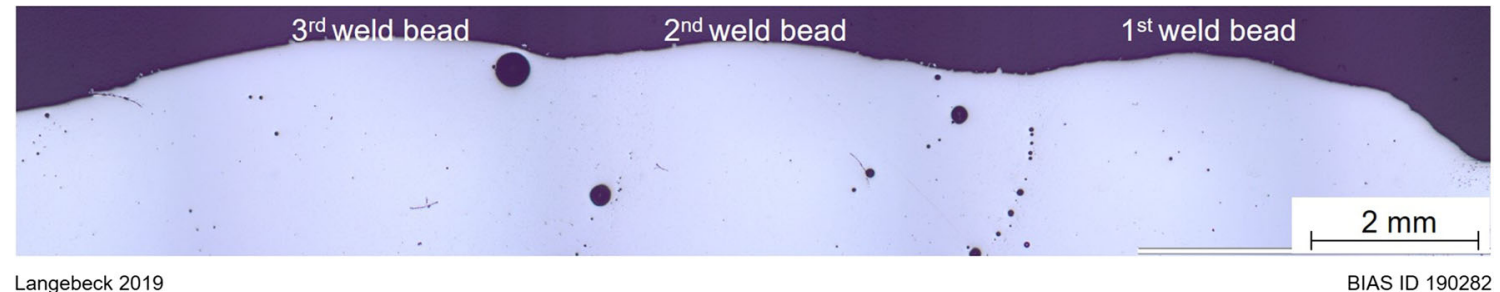

Fig. 7 Pore cluster along weld bead interface between first and second weld bead

- It is preferable to set a low horizontal overlapping when manufacturing layers to reduce the impact of the preceding weld bead on porosity.

Acknowledgements The authors gratefully acknowledge the collaboration with the company IBO GmbH and the Leibniz Institute for Materialoriented Technologies regarding their support of knowledge over the course of the research. The "BIAS ID" numbers are part of the figures and allow the retraceability of the results with respect to the mandatory documentation required by the funding organization.

Funding information The ZIM-project number ZF4063003SU7 was funded by the Federal Ministry for Economic Affairs and Energy (BMWi) via the German Federation of Industrial Research Associations $(\mathrm{AiF})$ in accordance with the policy to support the Central Innovations of Medium-Sized Enterprises (ZIM) on the basis of a decision by the German Bundestag.

Open Access This article is distributed under the terms of the Creative Commons Attribution 4.0 International License (http:// creativecommons.org/licenses/by/4.0/), which permits unrestricted use, distribution, and reproduction in any medium, provided you give appropriate credit to the original author(s) and the source, provide a link to the Creative Commons license, and indicate if changes were made.

\section{References}

1. Schmidt M, Merklein M, Bourell D, Dimitrov D, Hausotte T, Wegener K, Overmeyer L, Vollertsen F, Levy GN (2017) Laser based additive manufacturing in industry and academia. CIRP Ann 66:561-583. https://doi.org/10.1016/j.cirp.2017.05.011

2. Herzog D, Seyda V, Wycisk E, Emmelmann C (2016) Additive manufacturing of metals. Acta Mater 117:371-392. https://doi. org/10.1016/j.actamat.2016.07.019

3. Nowtny S, Brueckner F, Thieme S, Leyens C, Beyer E (2015) High-performance laser cladding with combined energy sources. J Laser Appl 27:S17001. https://doi.org/10.2351/1.4817455
4. Mahamood RM, Akinlabi ET (2015) Laser metal deposition of functionally graded Ti6Al4V/TiC. Mater Des 84:402-410. https:// doi.org/10.1016/j.matdes.2015.06.135

5. Bohlen A, Freisse H, Hunkel M, Vollertsen F (2018) Additive manufacturing of tool steel by laser metal deposition. Procedia CIRP 74:192-195. https://doi.org/10.1016/j.procir.2018.08.092

6. Singh A, Ramakrishnan A, Dinda G (2017) Direct laser metal deposition of Al 7050 alloy. SAE Technical Paper. https://doi.org/10. 4271/2017-01-0286

7. Freisse H, Vorholt J, Seefeld T, Vollertsen F (2015) Additive manufacturing of a deep drawing tool. Proc WLT Conference: Lasers in Manufacturing

8. Mondal M, Das H, Hong ST, Jeong BS, Han HN (2019) Local enhancement of the material properties of aluminium sheets by a combination of additive manufacturing and friction stir processing. CIRP Ann 68:289-292. https://doi.org/10.1016/j.cirp.2019.04.109

9. Katayama S (ed) (2013) Handbook of laser welding technologies. Elsevier

10. Jaegle EA, Sheng Z, Wu L, Lu L, Risse J, Weisheit A, Raabe D (2016) Precipitation reactions in age-hardenable alloys during laser additive manufacturing. JOM 68:943-949. https://doi.org/10.1007/ s11837-015-1764-2

11. Zhao H, White DR, DebRoy T (1999) Current issues and problems in laser welding of automotive aluminium alloys. Int Mater Rev 44: 238-266. https://doi.org/10.1179/095066099101528298

12. Reisgen U, Willms K, Wieland S (2017) Influence of storage conditions on aluminum 4043A welding wires. Weld J 96: 220-227

13. AlShaer AW, Li L, Mistry A (2014) The effects of short pulse laser surface cleaning on porosity formation and reduction in laser welding of aluminium alloy for automotive component manufacture. Opt Laser Technol 64:162-171. https://doi.org/10.1016/j. optlastec.2014.05.010

14. Spierings AB, Dawson K, Voegtlin M, Palm F, Uggowitzer PJ (2016) Microstructure and mechanical properties of as-processed scandium-modified aluminium using selective laser melting. CIRP Ann 65:213-216. https://doi.org/10.1016/j.cirp.2016.04.057

15. Kaufmann N, Imran M, Wischeropp TM, Emmelmann C, Siddique S, Walther F (2016) Influence of process parameters on the quality of aluminium alloy EN AW 7075 using selective laser melting (SLM). Phys Procedia 83:918-926. https://doi.org/10.1016/j. phpro.2016.08.096 
16. Katayama S, Seto N, Mizutani M, Matsunawa A (2000) Formation mechanism of porosity in high power YAG laser welding. Proc ICALEO 89:C-16. https://doi.org/10.2351/1.5059433

17. Dai D, Gu D (2016) Influence of thermodynamics within molten pool on migration and distribution state of reinforcement during selective laser melting of AIN/AlSi10Mg composites. Int J Mach Tools Manuf 100:14-24. https://doi.org/10.1016/j.ijmachtools. 2015.10.004

18. Haboudou A, Peyre P, Vannes AB, Peix G (2003) Reduction of porosity content generated during Nd: YAG laser welding of A356 and AA5083 aluminium alloys. Mater Sci Eng A 363:4052. https://doi.org/10.1016/S0921-5093(03)00637-3
19. Jeurgens LPH, Sloof WG, Tichelaar FD, Mittemeijer EJ (2002) Growth kinetics and mechanisms of aluminum-oxidefilms formed by thermal oxidation of aluminum. J Appl Phys 92:1649-1656. https://doi.org/10.1063/1.1491591

20. Hasani S, Panjepour M, Shamanian M (2012) The oxidation mechanism of pure aluminum powder particles. Oxid Met 78:179-195. https://doi.org/10.1007/s11085-012-9299-1

Publisher's note Springer Nature remains neutral with regard to jurisdictional claims in published maps and institutional affiliations. 